\title{
A consciência na obra de L.S. Vigotski: análise do conceito e implicações para a Psicologia e a Educação
}

\author{
Lia da Rocha Lordelo \\ Robinson Moreira Tenório
}

\section{Resumo}

O objetivo deste artigo teórico é analisar o conceito de consciência na obra de L. S. Vigotski. Partimos dos pressupostos de que Vigotski não só via o conceito de consciência como central em suas reflexões filosófico-metodológicas e em sua proposta de psicologia, como possuía, além das importantes contribuições dentro da Psicologia do Desenvolvimento e dos processos de aprendizagem, um valor fundamental enquanto pensador da Psicologia como ciência. Primeiramente, dedicamo-nos à transformação do conceito, desde um viés reflexológico até um caráter mais semiótico. A seguir, analisamos uma metáfora utilizada por Vigotski em um de seus textos, em que compara a consciência a um objeto refletido num espelho e faz uma analogia entre este processo e a ciência psicológica, seus pressupostos epistemológicos e metodológicos de investigação. Finalmente, a partir dessas reflexões, concluímos com a discussão de alguns possíveis impactos do estudo do conceito vigotskiano de consciência na Psicologia e na Educação.

Palavras-chave: Vygotsky, consciência, psicologia.

\section{Consciousness in L. S. Vigotski's work: analysis of the concept and its implications in Psychology and Education}

\begin{abstract}
The aim of this article is to analyze the concept of consciousness in the work of L.S. Vygotsky. We start with the assumption that Vygotsky not only saw the concept of consciousness as central to his philosophical-methodological reflections and in his psychology proposal, but also had, besides important contributions to Developmental Psychology and teaching-learning processes, a fundamental value as thinker of psychology as a science. Firstly, we dedicate ourselves to the concept transformation, from a reflexological to a semiotic view. Then, we analyze a metaphor used by Vygotsky in one of his texts, in which he compares consciousness to an object reflected in a mirror and makes an analogy between this process and psychological science, its epistemological and methodological investigation assumptions. Finally, we conclude the article discussing some possible implications of the study of the vygotskyan concept of consciousness in Psychology and Education.
\end{abstract}

Keywords: Vigotsky, conscience, psychology.

\section{La conciencia en la obra de L.S. Vigotski: análisis del concepto y consecuencias para la Psicología y la Educación}

\section{Resumen}

El objetivo de este artículo teórico es analizar el concepto de conciencia en la obra de L. S. Vigotski. Partimos de la presuposición de que Vigotski no solo veía el concepto de conciencia como central en sus reflexiones filosófico-metodológicas y en su propuesta de psicología, sino que también poseía, además de las importantes contribuciones dentro de la Psicología del Desarrollo y de los procesos de aprendizaje un valor fundamental como pensador de la Psicología como ciencia. Primero, nos dedicamos a la transformación del concepto, desde un sesgo reflexológico hasta un carácter más semiótico. A seguir, analizamos una metáfora utilizada por Vigotski en uno de sus textos, en que compara la conciencia a un objeto reflejado en un espejo y hace una analogía entre este proceso y la ciencia psicológica, sus presuposiciones epistemológicas y metodológicas de investigación. Finalmente, a partir de esas reflexiones, concluimos con la discusión de algunos posibles impactos del estudio del concepto vigotskiano de conciencia en la Psicología y en la Educación.

Palabras clave: Vygotsky, conciencia, psicología. 


\section{Introdução}

O objetivo deste artigo é fazer uma análise do conceito de consciência, presente na obra do psicólogo L. S. Vigotski, de um ponto de vista epistemológico. De modo geral, pensamos que Vigotski não só via o conceito de consciência como central em suas reflexões filosófico-metodológicas e em sua proposta de psicologia, como costumava avaliar a relevância de teorias psicológicas de acordo com a sua contribuição ao estudo do conceito (Zinchenko, 1985, p. 99). Daí, procederemos à análise do conceito vigotskiano de consciência, seus aspectos ontológico e epistemológico, isto é, sua natureza mesma e seu lugar e modo de investigação na ciência psicológica, bem como de algumas implicações do conceito para a educação.

O esforço teórico aqui empreendido parte precisamente da reflexão de que Vigotski possui, além das contribuições importantes e conhecidas dentro da Psicologia do Desenvolvimento e dos processos de aprendizagem, um valor fundamental enquanto pensador da Psicologia como ciência, tendo realizado, em diversos textos, reflexões filosóficas e metodológicas que buscavam legitimar o conhecimento psicológico produzido no início do século $\mathrm{XX}$, quando viveu a maior parte de sua curta vida (1896-1934). Podemos dizer que, dentro da produção científica em Psicologia no Brasil, as contribuições de caráter mais epistemológico de Vigotski não têm sido priorizadas e que, só nos últimos dez anos, este quadro vem se modificando, em especial através de estudos de alguns autores (Pino, 2000, 2005; Zanella, Reis, Titon, Urnau, \& Dassoler, 2007). Dessa forma, nosso estudo justifica-se pela escassez de trabalhos de natureza teóricocrítica sobre as reflexões produzidas por Vigotski, no âmbito da Psicologia enquanto ciência. Este "outro" Vigotski já foi resgatado por autores com Van der Veer e Valsiner, os quais afirmam que o autor, mais do que um psicólogo preocupado com análises empíricas de fenômenos experimentais, era antes de tudo um "filósofo/metodologista em seu coração" (1996, p.44). É este "outro" Vigotski, metodólogo e pensador da ciência, que procuraremos resgatar, através da análise do conceito de consciência em sua obra.

Para proceder a esta análise, faremos uso de alguns textos específicos produzidos por Vigotski, quais sejam": "A Consciência como Problema da Psicologia do Comportamento" (1999a), "Os Métodos de Investigação Reflexológicos e Psicológicos" (1999b), "O Problema da Consciência" (1999c) e "O Significado Histórico da Crise na Psicologia" (1999d), todos pertencentes ao volume publicado no Brasil sob o título de Teoria e Método em Psicologia (1999).

Em O Significado Histórico da Crise na Psicologia, importante escrito de natureza metodológica e filosófica, Vigotski diagnostica o que ele chama de crise na Psicologia do início do século XX. Tal crise caracterizava-se, em sua

1 Por conta das limitações colocadas pelo tamanho reduzido dos artigos científicos, os textos foram escolhidos por proporem mais explicitamente uma reflexão epistemológica ou por conterem, no título, já uma proposta de discutir o conceito de consciência. avaliação, pelo fato de as diversas escolas psicológicas à época da crise serem categorizadas em dois polos básicos: uma corrente científico-natural materialista e outra dita idealista ou espiritualista. Sistemas teóricos como o behaviorismo (conhecido atualmente como behaviorismo metodológico), a psicanálise, a reflexologia russa, a psicologia personalista de William Stern e a psicologia subjetivista de origem alemã encaixavam-se em um ou outro polo da controvérsia. Assim, se uma tendência recorria a um polo científico-naturalista e rejeitava a ideia de um fenômeno psíquico irredutível ao físico em termos de propriedades e substâncias, a outra posicionava-se no outro oposto do polo: afirmava a existência de um fenômeno psíquico formado por uma substância própria e isto dificultava sua sujeição a métodos de apreensão e análise rigorosamente científicos. Em palavras mais simples, o dilema era a existência de uma ciência que negava o aspecto subjetivo ou a existência de uma psicologia que, aceitando o fenômeno psíquico, deixava de ser ciência². É nesta espécie de encruzilhada que se encontrava o fenômeno psicológico. Para Vigotski, a proposição do conceito de consciência era uma espécie de resposta para a dicotomia entre correntes da psicologia que unificaria, assim, a ciência psicológica.

\section{Transformação no conceito vigotskiano de consciência}

A primeira coisa a perceber aqui é que, mesmo sendo proposto como categoria fundamental para a sua psicologia, o conceito de consciência foi, ao longo dos anos, desenvolvendo-se e transformando-se dentro dos trabalhos do autor. Há alguns escritos que abordam este tema de forma mais explícita: o primeiro seria "Os Métodos de Investigação Reflexológicos e Psicológicos” (1999b), a famosa comunicação de 1924 apresentada num congresso em São Petersburgo que "abriu as portas" da psicologia para Vigotski. Há ainda "A Consciência como Problema da Psicologia do Comportamento" (1999a), fruto de sua primeira conferência quando já no Instituto de Psicologia em Moscou, ao que tudo indica em 1925; "O Significado Histórico da Crise na Psicologia", terminado entre 1926 e 1927; e "A Construção do Pensamento e da Linguagem" (2001), publicado já no fim de sua vida, em 1934. Há ainda uma compilação e notas de estudos de seminários feitos por alunos e colegas da equipe de pesquisa de Vigotski entre os anos de 1933 e 1934, intitulada "O Problema da Consciência" (1999c). Inicialmente publicada por Leontiev nos anos sessenta, esta compilação, por conter fragmentos de anotações feitas por outras pessoas que não o próprio psicólogo, provavelmente contém problemas em sua edição,

2 O livro de Luís Cláudio Figueiredo (1996, p. 22) também localiza este dilema de forma bastante semelhante. $\mathrm{O}$ autor declara que, para instituir a ciência psicológica, a psicologia se vê obrigada, a um só tempo, a reconhecer e desconhecer seu objeto. Se não o reconhece, não se legitima como ciência independente, bem podendo ser anexada a outras ciências, como a medicina, a pedagogia etc. Se o reconhece, não se legitima enquanto ciência, já que não é capaz de formular leis gerais com caráter preditivo. 
o que requer cuidado redobrado quando utilizada como fonte de pesquisa.

De fato, se tomarmos os textos em ordem de escrita cronológica, perceberemos uma mudança na forma de conceituar a consciência. Esta mudança é percebida, em particular, por Davydov e Radzikhovskii (1985) e Rivière (1985) e tem como ponto decisivo, para este último autor, a transição entre um viés reflexologista, nos idos de 1924, para uma concepção semiótica ou mediacional do conceito.

Em "Os Métodos de Investigação Reflexológicos e Psicológicos" (1999b), Vigotski apresenta-se pela primeira vez a um grande público de psicologia; sua comunicação procurava criticar justamente a reflexologia, a corrente psicológica dominante nos meios acadêmicos russos. Ele afirmava que a reflexologia tornava-se mais problemática à medida que investia no estudo de formas de comportamento humano cada vez mais complexas, por conta da definição reflexológica de qualquer comportamento como um sistema de reflexos condicionados. Para Vigotski, resumir todo e qualquer comportamento a tal denominador comum era incorrer em reducionismo; e era também reducionista a atitude de, à maneira do behaviorismo metodológico fundado por Watson, não levar em conta a consciência como mais uma espécie de comportamento possível de ser observado e estudado.

Vemos que Vigotski critica o ponto de vista da reflexologia (também conhecida como psicologia objetiva, inicialmente fundada por Bekhterev), mas propõe uma espécie de meio-termo ao sugerir a possibilidade de a consciência ser estudada pelos reflexólogos. Utilizando a linguagem da corrente que criticava, ele define a consciência como "um mecanismo de transmissão entre sistemas de reflexos" (1999b, p. 15). Chega a afirmar que "dar-se conta significa transferir certos reflexos para outros. O inconsciente baseia-se psiquicamente em que alguns reflexos não se transmitem a outros sistemas." (1999b, p. 14) Uma passagem um pouco mais longa esclarece melhor seu argumento:

Surge a pergunta: por que admitimos o estudo dos reflexos verbais em sua integridade e inclusive depositamos nesse campo as maiores expectativas e não levamos em consideração esses mesmos reflexos quando não se manifestam externamente mas sem dúvida existem objetivamente? Se pronuncio em voz alta, para que o experimentador ouça, a palavra "tarde", que me surgiu por associação, isto é considerado uma reação verbal, um reflexo condicionado. Mas se pronuncio a palavra para mim mesmo, sem que seja ouvida, se a penso, deixa por isso de ser um reflexo e se altera sua natureza? E onde está o limite $^{3}$ entre a palavra pronunciada e a não pronunciada? (1999b, p. 10)

É um pouco mais sutil a crítica de Vigotski aqui, mas podemos perceber que, conquanto argumente de dentro do sistema reflexológico acerca da existência da consciência, ele afirma algo bastante radical dentro da teoria: que os

3 Os itálicos são do próprio autor. eventos da consciência, apesar de não se manifestarem exteriormente, possuíam existência objetiva. Este é o ponto crucial de sua conferência e o que pode ter causado tanta polêmica no congresso de 1924. Outra declaração em tom mais inflamado torna mais claro este ponto:

Falemos claro. Os enigmas da consciência, da psique, não podem ser eludidos com subterfúgios nem metodológicos nem teóricos. Não se pode fazer rodeios para deixar a consciência de lado. (...) Psicologicamente a consciência é um fato indubitável, uma realidade primordial e um fato, não secundário, nem casual, de enorme importância. Ninguém o discute. Podemos adiar o problema, mas não eliminá-lo por completo. (1999b, p. 27)

Vigotski arremata essa declaração lembrando que tudo isso deve ser resolvido experimentalmente, de acordo com procedimentos objetivos. Ele recomenda aos reflexólogos que abandonem o materialismo da fisiologia ao qual estão aprisionados e aceitem o desafio de serem materialistas na psicologia.

Para uma plateia de reflexólogos em sua maioria, a proposição de Vigotski pode ser considerada, no mínimo, corajosa. Ainda assim, o mecanismo através do qual ele propõe que se estude a consciência é tão reflexológico quanto o do estudo de um comportamento qualquer. A diferença básica é que, em um evento psíquico, o reflexo produzido por determinada sensação torna-se, em seguida, excitante para um novo reflexo: esta relação, chamada por Vigotski reflexo-excitante reversível, é uma relação entre reflexos que não ocorre no caso de comportamentos mais simples.

Aproximadamente um ano depois, em "A Consciência como Problema da Psicologia do Comportamento" (1999a), outras questões já passam a se tornar importantes na defesa de Vigotski do conceito de consciência. Nas palavras de Rivière (1985), o citado artigo de Vigotski de 1925 possui como característica principal a tentativa de conjugar a categoria do reflexo com a ideia da origem social da consciência. Neste sentido, há, sim, uma atitude bastante crítica em relação à reflexologia, visto que ele considera extremamente problemática a admissão da principal premissa reflexológica de que seria possível explicar todo o comportamento humano sem recorrer a fenômenos subjetivos. No entanto, como ele já apontava na comunicação "Os Métodos de Investigação Reflexológicos e Psicológicos" (1999b), o problema estava justamente em considerar que o fenômeno psíquico possuísse uma natureza subjetiva, inacessível experimentalmente e, consequentemente, não científica.

Entre a palestra que o fez ser convidado para trabaIhar em Moscou em 1924 e a primeira fala pública que fez depois de ter começado a trabalhar, em 1925, existe, portanto, uma ligação compreensível. A nosso ver, a maior distinção entre os dois textos seria que, no segundo momento, o autor abandona a tentativa de buscar dentro da reflexologia ou da reatologia uma metodologia adequada para investigar os fenômenos da consciência, afirmando uma "urgente necessidade de elaborar uma nova metodologia para investigar os 
reflexos inibidos" (1999a, p. 77) ou, ainda, numa observação um pouco mais irônica, "uma capitulação completa da metodologia puramente reflexológica, cuja utilização deu bons resultados no caso dos comportamentos dos cachorros" (1999a, p. 78).

A origem social da consciência, mais especificamente localizada na linguagem e no comportamento social, é uma ideia que também se encontra presente nos dois trabalhos; ela será, no entanto, melhor desenvolvida anos mais tarde, logo em 1926, em "O Significado Histórico da Crise na Psicologia", no manuscrito "Historia del Desarrollo de las Funciones Psíquicas Superiores" (1995) de 1931 e, em 1934, em Pensamento e Linguagem. No artigo de 1926, encontra-se, no entanto, uma reflexão de fundo epistemológico mais sistematizada acerca do problema da consciência e da própria psicologia e é a ela que nos dedicaremos agora.

\section{A consciência no espelho: uma nova epistemologia para a psicologia}

Foi possível perceber, nos dois artigos analisados, a adesão inicial de Vigotski ao ponto de vista reflexológico, paralelamente aos primeiros comentários acerca de uma possível origem social da consciência. Ele chega a afirmar a importância da linguagem, do comportamento social e da relação com o outro na formação da consciência, e seus próximos escritos, de certa maneira, são o desenvolvimento dessas ideias ainda embrionárias.

Em "O Significado Histórico da Crise na Psicologia" (1999d), a consciência é discutida não só como objeto fundamental de estudo para a psicologia, mas também na forma de um conceito que, quando examinado de perto, produz uma reflexão epistemológica abrangente, a qual compreende algumas antinomias típicas da ciência e da filosofia, outras correntes psicológicas e seus problemas metodológicos. Esta é uma promessa e tanto, esperamos agora examiná-la para que se torne compreensível.

A ideia central defendida por Vigotski nesse artigo é a crise na psicologia e o que ela significa e prenuncia. Para o autor, como já dissemos anteriormente, distinguiam-se, àquela época, dois grandes blocos de teorias psicológicas. Resumidamente, os caminhos da psicologia seriam estes: ou o da ciência, que, neste caso, deveria ser capaz de explicar fenômenos (rejeitando o que havia neles de psíquico ou subjetivo); ou o do conhecimento de visões particulares sobre o que viria a ser o fenômeno psíquico (assim impossibilitando sua existência como ciência). O que parece chamar a atenção, entretanto, é o argumento que Vigotski usa para atribuir significado à crise: esse significado residiria, para ele, na formulação equivocada e confusa do problema gnoseológico ${ }^{4}$, ou melhor, na confusão entre o problema gnoseológico (ou epistemológico) e o ontológico. Parece que o problema

4 Na tradução do artigo do russo para o inglês, consta a palavra epistemológico ao invés de gnoseológico; a palavra gnoseológico aparece também na tradução para o espanhol. Não estamos considerando significativas as eventuais diferenças entre os termos. fundamental estaria em confundir a relação entre espírito e matéria com a relação entre sujeito e objeto. "Quando isto é feito", diz Vigotski, "é comum identificar o subjetivo com o psíquico, e a partir daí se conclui que o psíquico não pode ser objetivo" (1999d, p. 379). Ou seja, o fenômeno psíquico, ou espiritual, é às vezes considerado como sendo aquilo que tem natureza subjetiva. Certamente nossa psique ou nossa consciência ${ }^{5}$ pode ser (e é) "subjetiva" - ou seja, ela pode ser de natureza não material -, mas, sendo assim, "subjetivo" não é o termo que devemos utilizar, segundo Vigotski, pois ele produz uma grave confusão conceitual ${ }^{6}$. O psicólogo nos chama a atenção para que não confundamos a consciência, enquanto um dos termos da antinomia sujeito-objeto, com a consciência empírica, psicológica, aquela que é, por definição, objeto de estudo da psicologia.

Com o objetivo de esclarecer essa discussão, seguiremos mais um pouco o raciocínio feito por Vigotski (1999d, pp. 381-382). Ele ilustra: se perguntarmos a um materialista e a um idealista o que devemos estudar, o ato tal como é, ou o ato tal como eu o represento, o primeiro responderá o ato em si e o segundo, a percepção que ele tem do ato. De outra forma, o que devemos estudar: o pensamento ou o pensamento sobre o pensamento? Para Vigotski, sem sombra de dúvida devemos estudar o pensamento em si - ele pede, neste caso, o auxílio de Marx, em sua afirmação de que, se a essência e a forma de manifestação das coisas coincidissem, toda a ciência seria desnecessária (Marx, 1985, p. 939). É aí que podemos nos perguntar: se nós, psicólogos, cientistas humanos, estudamos o fenômeno psíquico em si e admitimos que ele possui natureza e existência objetivas, o que será, então, dos fenômenos subjetivos? Quem vai estudar esse tipo de fenômeno, "isso que parece para cada um ${ }^{7}$ ?" (Vigotski, 1999d, p. 382).

"Mas o problema do que as coisas 'parecem' é também algo que 'parece' um problema”, continua Vigotski (1999d, p. 382). A falsidade desse problema está, para ele, novamente na confusão entre gnoseologia e ontologia.

Em gnoseologia, aquilo que parece existe, mas afirmar que aquilo é realmente a existência é falso. Em ontologia, o que

5 De modo geral, temos também usado de forma intercambiável os termos "consciência" e "psique". Certamente quando Vigotski escolheu o primeiro termo, imprimiu a ele características próprias é o que estamos tentando mostrar; ainda assim, quando usamos um nome no lugar do outro, é porque pretendemos nos referir, independente de nomenclaturas, àquilo que seja, por definição, o objeto de estudo da psicologia.

6 Grande parte do esforço de Vigotski nessa discussão consiste, ao nosso ver, em atribuir uma natureza objetiva ao que denominamos fenômenos psicológicos - a psique, a consciência, ou subjetividade. É por esta razão que ele tenta afastar a antinomia "objetivo $X$ subjetivo" de suas reflexões sobre a consciência - por esta ser uma distinção de fundo epistemológico, quando o que está em jogo é uma asserção ontológica - que diz respeito à existência mesma dos fenômenos psicológicos

7 Itálicos no original. 
parece não existe em absoluto. Ou os fenômenos psíquicos existem e então são materiais e objetivos, ou não existem e não podem ser estudados. É impossível qualquer ciência só sobre o subjetivo, sobre o que parece ${ }^{8}$, sobre fantasmas, sobre o que não existe. (...) Não cabe dizer: no mundo há coisas reais e irreais - o irreal não existe. $O$ irreal deve ser explicado como a não coincidência, como a relação entre duas coisas reais; o subjetivo como a consequência de dois processos objetivos. (1999d, p. 386)

A explicação de Vigotski pode soar, em algum momento, um tanto intrincada; alguns parágrafos depois, porém, ele utiliza a metáfora do espelho para pensar o conceito de consciência no contexto da relação entre epistemologia e ontologia. Aqui, ao nosso ver, suas reflexões tornam-se mais claras. Vejamos:

Um objeto - uma mesa, por exemplo - é refletido num espelho. Chamemos de $\underline{\mathbf{A}}$ a mesa e de $\underline{\mathbf{a}}$ o seu reflexo no espelho. $\underline{\mathbf{X}}$ é o processo de reflexão ${ }^{9}$ da luz que ocorre no espelho, refletindo a mesa. Aqui, não podemos dizer que a (o reflexo da mesa) é tão real quanto $\underline{\mathbf{A}}$ (a mesa em si); tampouco dizer que a é falso; ocorre que a é real de outra forma. O reflexo a é o resultado aparente que parte de $\underline{\mathbf{A}}$ e de $\underline{\mathbf{X}}$. Entretanto, conhecendo $\underline{\mathbf{A}}$ e $\underline{\mathbf{X}}$, é possível estudar, explicar, prever e ainda transformar o reflexo $\underline{\mathbf{a}}$.

Para Vigotski, a filosofia e a ciência ocidentais tradicionalmente focalizam, em seus processos de investigação, o objeto em si, $\underline{\mathbf{A}}$, ou apenas o reflexo, a imagem, ‥ De um ponto de vista dialético (na ciência que ele propunha), é necessário estudar a como um resultado, uma consequência do objeto em si, já que o reflexo não existe por si só: é preciso relacionar a mesa ao espelho e também às leis que ocasionam o reflexo. Se a consciência seria $\underline{\mathbf{a}}$, o reflexo, $\underline{\mathbf{A}}$ seria a existência, é o que Vigotski indica alguns parágrafos depois (1999d, p. 388); finalmente, $\underline{\mathbf{X}}$, as leis de reflexão da luz no espelho, seria o processo que ocorre na consciência. A autora Dorothy Robbins (2003) resgata essa metáfora em artigo e sugere que essas leis de reflexão seriam o processo de internalização e mediação que ocorre através da linguagem e de outros signos. Cremos, certamente, que levar a metáfora às últimas consequências cause-nos alguns prejuízos conceituais, pois ao passo em que procuremos achar "equivalentes" para as "letras" $\underline{\mathbf{A}}, \underline{\mathbf{a}}$ e $\underline{\mathbf{X}}$, respectivamente, corremos o risco de cristalizar as posições de cada categoria e distorcer as eventuais relações de complementaridade ou pertencimento que existem entre elas - e incorremos, aí, numa simplificação bastante perigosa, a nosso ver. Em verdade, a própria Robbins, ao estudar essa metáfora, lembra, no início de seu artigo, que uma metáfora não é completa e que tampouco pode realmente ilustrar fatos empíricos (Fichtner, 1999, conforme citado por Robbins, 2003), mas ilustrar relações teóricas. No

8 Os itálicos desta citação também estão no original.

9 Nas edições em inglês e em português, Vigotski usa, incorretamente, o termo físico "refração". Aproveitando o fato de estarmos fazendo aqui uma citação indireta, substituímo-lo pela palavra correta, "reflexão". caso do exemplo do espelho, acreditamos que Vigotski tinha um objetivo principal: mostrar que a consciência humana, vista por algumas correntes psicológicas como um evento interno e às vezes de difícil acesso e investigação, torna-se um resultado aparente, uma consequência da relação entre a realidade e o processo de internalização desta através da linguagem e de outras ferramentas simbólicas - o que não significa que não possamos estudá-la. Significa, sim, que, se conhecermos, no caso, $\underline{\mathbf{A}}$ e $\underline{\mathbf{X}}$, conheceremos a consciência e ainda, em particular, as funções psicológicas superiores a cujo estudo Vigotski se dedicou.

A analogia proposta por Vigotski não é exatamente original na literatura científica e filosófica - especialmente a de orientação marxista. Ela pode ser relacionada, em primeiro lugar, a um conhecido princípio do materialismo dialético, de acordo com o historiador da ciência Graham (1987): o de que a existência determina a consciência. Este é uma máxima presente em textos de Marx $\left(1977^{10}\right)$, Marx e Engels (1999) e Lenin, posteriormente (1982), de posse desta premissa, dedica-se bastante a teorizar sobre o que, para ele, seria a fundação da teoria materialista do conhecimento: a consciência é uma imagem do mundo exterior e, sem este mundo, nem a consciência nem quaisquer sensações existiriam. Não à toa, as palavras reflexo e imagem são frequentemente utilizadas para se referir à epistemologia materialista nessa obra de Lenin.

Pensamos que é interessante perceber os significados que a metáfora do espelho carrega no contexto das reflexões epistemológicas de Vigotski. Em introdução a uma coletânea de textos em epistemologia, Manuel Maria Carrilho (1991) coloca como uma das questões mais recentes deste campo de estudos justamente as "condições históricas" da constituição do conhecimento, além das "condições psicogenéticas" de sua aquisição. Seria o conhecimento algo de origem exclusivamente subjetiva? Vigotski já procurava responder a esta pergunta em seu já citado artigo, dissolvendo e reposicionando falsas antinomias como "conceito X fato" ou "realidade X pensamento" e, ainda, "sujeito X objeto". Como tentamos mostrar acima, a metáfora vigotskiana do espelho é, em grande medida, uma tentativa de pensar as categorias de subjetivo e objetivo e se, nas palavras de Carrilho (1991), podemos pensar num dos sentidos da palavra "epistemologia" como uma oposição à "ontologia", o argumento de Vigotski quanto à suposta confusão entre estes dois termos parece possuir consistência teórica - em especial no que tange a seu diagnóstico da crise na psicologia.

\section{Algumas implicações para a educação ou um outro Vigotski}

10 Para sermos mais precisos, a afirmação de Marx no Prefácio da Contribuição à Crítica da Economia Política (1977, p. 24) é a de que "... não é a consciência dos homens que determina seu ser; é o seu ser social que, inversamente, determina a sua consciência”. De qualquer forma, permanece, na citação, a relação de determinação a que havíamos nos referido, e na direção vida (ou existência) $\rightarrow$ consciência. 
É nosso intento, neste artigo, mostrar um Vigotski um pouco diferente do habitual, principalmente no cenário acadêmico brasileiro. O "Vigotski habitual" tornou-se, a partir dos anos oitenta, uma das grandes referências nas discussões no campo da psicologia da educação, do desenvolvimento infantil e das relações ensino-aprendizagem na escola, ao lado de autores como Jean Piaget e Henri Wallon. A relação aprendizagem-desenvolvimento (Oliveira, 1993), a qual se concretiza na noção de zona de desenvolvimento proximal, é uma ideia fundamental no corpo de reflexões trazidas pelo psicólogo soviético. São ainda importantes o processo de formação de conceitos, a importância do brinquedo na educação infantil (Cerisara, 2000) e o papel do outro na construção do conhecimento (Rego, 1997).

Estes são tópicos que ressoam na prática direta do educador e de outros profissionais que atuem no campo da pedagogia principalmente. Neste sentido, entretanto, Marta Kohl de Oliveira $(1993,2000)$ faz uma reflexão importante: ela lembra que o campo da educação é um dos que possui uma relação mais problemática entre prática e teoria; enquanto, de um lado, os professores esperam da teoria um "como fazer" rápido e eficiente, o pesquisador, de modo geral, busca em sua investigação produzir um conhecimento com algum poder explicativo, mas que não necessariamente gera propostas de atuação diretas. No caso de Vigotski, este problema quase passa a adquirir o caráter de solução: seu trabalho, por conta do pouco tempo que teve para se desenvolver, não possui indicações muito precisas sobre como deve agir o professor em sala de aula ou qual a melhor estratégia para desenvolver, no tempo adequado, a linguagem de uma criança (embora sua preocupação com a prática fosse grande), por outro lado, ele pode inspirar uma reflexão importante sobre como funciona o ser humano, de que ponto de vista realizar a pesquisa em educação e outras áreas relacionadas.

Apesar disso, certamente entendemos Vigotski como um autor extremamente importante para o campo da educação e é neste sentido que resgatamos a reflexão feita por Marta Kohl: para resgatar também este "outro" Vigotski. Este pesquisador, sobre o qual nos debruçamos aqui, elaborou reflexões de cunho epistemológico e metodológico que amparam problemas atuais dentro das ciências humanas de modo geral e, mais especificamente, na psicologia e na pedagogia talvez nisto resida boa parte de sua atualidade. Dessa forma, isso não significa que ele não seja fundamental para o campo da educação. Mesmo uma reflexão epistemológica, ou ela em especial, ressoa no campo da prática pedagógica e também por esta razão procuramos resgatar esse tipo de crítica.

Este Vigotski "normativo", cujas ideias são rapidamente transformadas em orientações práticas, deve ser minimamente repensado e, em alguns casos, combatido porque ele não existe, propriamente. $E$ se, por um lado, o que havia de orientação ou "como fazer" em suas obras vai gradativamente perdendo o sentido, já que foi, como quase todo conhecimento, construído em condições sociais e históricas muito específicas, o valor crítico e epistemológico dos textos não tem uma data exata para "expirar": seu caráter menos contingente torna possível o diálogo com diferentes condições e contextos e é difícil, por conta disso, considerálo normativo em alguma instância. Esta característica não é exclusiva dos textos de Vigotski; certamente, em todo autor cujo pensamento possua posicionamento crítico acerca da construção do conhecimento (tanto em ciência quanto em outras áreas), é possível dele extrair uma reflexão para o tempo presente. Para nós, este é um grande valor da epistemologia.

Pode ser um modo de pensar dialético dizer que, diante dessas colocações, sabemos quais não são as implicações do pensamento de Vigotski, em especial de seu conceito de consciência, para a educação. Sabemos o que não devemos fazer. É muito precipitado extrair de conceitos como "consciência" e "significado" orientações sobre como agir numa situação específica, por exemplo, em sala de aula.

No entanto, existe, em educação, outro campo de reflexões onde a noção de consciência é central. Este conceito foi um tema de interesse e pesquisa frequentes na obra de educadores famosos - entre eles, o pernambucano Paulo Freire (1921-1997), o qual, em sua pedagogia crítica, enfatizou o papel da educação popular na formação da consciência crítica (Freire, 1986). Embora não devamos equivaler o conceito de consciência psicológica (tal qual proposto por Vigotski) ao de consciência crítica de Freire, há, pelo menos, uma influência em comum a ambos os autores: o marxismo. Talvez seja por influência do marxismo que o conceito de consciência é tão importante para esses teóricos; mas, decerto, era a consciência de classe o que mais interessava a Marx. Já no caso do clássico livro de Georges Snyders, Escola, Classe e Luta de Classes (2005), vemos a defesa de uma possível escola, de posse de conceitos marxistas como o de luta de classes. Embora não faça uso explícito do conceito de consciência, o autor francês refere-se a este de forma indireta quando, ao assumir a escola como um local de contradições dialéticas, invoca "a iniciativa, a capacidade e a alegria de agir por si próprio, de crescer e de dirigir o seu crescimento" (2005, p. 119) para fazer da escola um local que lute pela democracia e pelo fim das desigualdades econômicas e sociais.

No caso específico de Vigotski e da proposição de seu conceito de consciência no âmbito da psicologia, acreditamos que haja algumas reflexões das quais a educação possa se beneficiar. Podemos, primeiramente, pensar na escola como um local privilegiado de desenvolvimento dos processos psíquicos que compõem a consciência, já que é no contexto escolar que as crianças passam grande parte de seu tempo. Aliado a isso, há a natureza material e objetiva do fenômeno da consciência e sua formação através da cultura e de seus instrumentos (físicos e simbólicos). Estes fatores ajudam-nos a pensar na situação, no ambiente em que se dão os processos de ensino e aprendizagem, e podem significar que devemos estar atentos aos elementos que constituem essas situações pedagógicas e nas relações entre estes elementos. E, de forma mais geral, a ideia de uma consciência formada pela história em seus diferentes níveis pode auxiliar-nos a conceber também uma escola cuja 
análise histórica seja fundamental para sua compreensão e contínua transformação. Assim, reafirmamos a importância, inclusive no âmbito da educação, de estudarmos de forma crítica o conceito de consciência na obra de L.S. Vigotski.

\section{Conclusão}

Percorrendo alguns textos de Vigotski, vimos que o conceito de consciência passou de um viés mais estritamente reflexológico para um de natureza mais social e semiótica - por conta, no caso, da proposição, em um de seus escritos, do significado da palavra como unidade de análise psíquica $^{11}$. Outra reflexão importante foi o resgate da metáfora do espelho, utilizada por Vigotski em "O Significado Histórico da Crise na Psicologia" (1999d) para ilustrar a condição epistemológica da categoria consciência. Ele declara, no artigo, que os dualismos em que incorrem algumas teorias psicológicas devem-se a uma confusão entre epistemologia e ontologia. Essa confusão ocorre quando tomamos por subjetivo um evento psíquico, quando este último, em verdade, tem natureza objetiva. Assim, comparando a consciência a um reflexo no espelho, ele afirma que devemos estudá-la não como algo totalmente real nem como uma imagem ou ilusão simplesmente, e sim como um evento que é real de outra forma. A consciência deve ser estudada como um fenômeno resultante da realidade e da internalização desta.

Após essas reflexões, dedicamo-nos a analisar algumas implicações deste conceito para o campo da Educação. Concluímos que pode ser bastante precipitado, quando não equivocado, extrair de um conceito como o de "consciência" algum tipo de fórmula ou procedimento direto de atuação em sala de aula, por exemplo. Isto é problemático por dois motivos, a nosso ver: primeiro, que o próprio conceito proposto por Vigotski tem, como tentamos mostrar, muito mais o intuito de produzir uma reflexão crítica que o de produzir uma aplicação prática na ciência psicológica. Certamente ele poderá e deverá produzir aplicações, mas o trajeto que nos leva de um conceito teórico até seu manejo no cotidiano profissional é mais complexo do que pensamos. Um segundo motivo é o fato de que a própria Educação não deve ser vista como uma ciência normativa (ao contrário da Psicologia, que infelizmente se construiu justamente sob a égide do que deve ser o "normal" e do que se desvia deste formato). Desse modo, parece-nos praticamente impossível, de posse do conceito de "consciência", chegar a conclusões sobre o que um educador deve ou não fazer na sua prática profissional, por exemplo. Mas lembramos que há todo um conjunto de reflexões que pode e deve ser feito ao tomarmos este con-

11 Para uma discussão mais aprofundada acerca da unidade de análise na obra vigotskiana, ver Lordelo, L. da R. (2007). A Consciência como Objeto de Estudo na Psicologia de L.S. Vigotski: uma reflexão epistemológica. Dissertação de Mestrado, Programa de Pós Graduação em Ensino, Filosofia e História das Ciências, UFBA/UEFS, Salvador. Disponível em : http://www.ppgefhc.ufba.br/ dissertacoes.htm ceito para análise, e pensamos que tanto a Educação quanto a Psicologia beneficiam-se bastante deste esforço de crítica teórica.

\section{Referências}

Carrilho, M. M., \& Sàágua, J. (1991). Objectivos e fronteiras do conhecimento. Em M. M. Carrilho (Org.), Epistemologia: posições e críticas. Lisboa: Fundação Calouste Gulbenkian.

Cerisara, A. B. (2000). A educação infantil e as implicações pedagógicas do modelo histórico-cultural. Cadernos CEDES, 35, 78-95.

Davydov, V. V., \& Radzikhovskii, L. A. (1985). Vygotsky's theory and the activity-oriented approach in psychology. Em J. V. Wertsch (Ed.), Culture, communication and cognition: vygotskyan perspectives (pp. 33-65). New York: Cambridge UP.

Figueiredo, L. C. M. (1996). Matrizes do pensamento psicológico. Petrópolis, RJ: Vozes.

Freire, P. (1986). Pedagogia do oprimido. Rio de Janeiro: Paz e Terra.

Graham, L. (1987). Science, philosophy, and human behavior in the Soviet Union. New York: Cambridge University Press.

Lénin, V. I. (1982). Materialismo e Empiriocriticismo. Lisboa: Avante.

Lordelo, L. da R. (2007). A Consciência como Objeto de Estudo na Psicologia de L.S. Vigotski: uma reflexão epistemológica. Dissertação de Mestrado, Programa de Pós Graduação em Ensino, Filosofia e História das Ciências, UFBA/UEFS, Salvador.

Marx, K. (1977). Prefácio. Em K. Marx, Contribuição à crítica da economia política. São Paulo: Livraria Martins Fontes Editora.

Marx, K. (1985). O Capital: Crítica da economia política (Vol. IV). São Paulo: DIFEL Difusão Editorial S.A.

Marx, K., \& Engels, F. (1999). A ideologia alemã. São Paulo: Editora Hucitec.

Oliveira, M. K. de. (1993). Vygotsky: aprendizado e desenvolvimento, um processo sócio-histórico. São Paulo: Scipione.

Oliveira, M. K. de. (2000). O pensamento de Vygotsky como fonte de reflexão sobre a educação. Cadernos CEDES, 35, 11-18.

Pino, A. (2000). O social e o cultural em Vigotski. Cadernos CEDES, 21(71), 45-78

Pino, A. (2005). Vigotski: as marcas do humano. São Paulo: Cortez Editora. 
Rego, T. C. (1997). Vygotsky: Uma perspectiva histórico-cultural da educação. Rio de Janeiro: Vozes.

Rivière, A. (1985). La psicología de Vygotski. Madrid: Visor.

Robbins, D. (2003). Vygotsky's non-classical dialectical metapsychology. Journal for the Theory of Social Behaviour, 33(3), 303-312.

Snyders, G. (2005). Escola, classe e luta de classes. São Paulo: Centauro Editora.

Van der Veer, R., \& Valsiner, J. (1996). Vygotsky: uma síntese. São Paulo: Edições Loyola.

Vigotski, L. S. (1995). Historia del desarrollo de las funciones psíquicas superiores. Em L. S. Vygotski, Obras Escogidas (Vol. 3). Madrid: Visor.

Vigotski, L. S. (1999a). A consciência como problema da psicologia do comportamento. Em L. S. Vigotski, Teoria e método em psicologia (pp. 55-85). São Paulo: Martins Fontes.

Vigotski, L. S. (1999b). Os métodos de investigação reflexológicos e psicológicos. Em L. S. Vigotski, Teoria e método em psicologia (pp. 3-55). São Paulo: Martins Fontes.
Vigotski, L. S. (1999c). O problema da consciência. Em L. S. Vigotski, Teoria e método em psicologia (pp. 171-189). São Paulo: Martins Fontes.

Vigotski, L. S. (1999d). O significado histórico da crise na psicologia. Em L. S. Vigotski, Teoria e método em psicologia (pp. 201-417). São Paulo: Martins Fontes.

Vigotski, L. S. (2001). A construção do pensamento e da linguagem. São Paulo: Martins Fontes.

Zanella, A. V, Reis, A. C. dos, Titon, A. P., Urnau, L. C., \& Dassoler, T. R. (2007). Questões de método em textos de Vygotski: contribuições à pesquisa em Psicologia. Psicologia \& Sociedade, 19(20), 25-33.

Zinchenko, V. P. (1985). Vygotsky's ideas about units for the analysis of mind. Em J. V. Wertsch (Ed.), Culture, communication and cognition: vygotskyan perspectives (pp. 94-118). New York: Cambridge UP.

\section{Sobre os Autores}

Lia da Rocha Lordelo (lialordelo@gmail.com)

Instituto de Psicologia da Universidade Federal da Bahia, Salvador, Bahia.

Robinson Moreira Tenório (rmtenorio@uol.com.br)

Faculdade de Educação da Universidade Federal da Bahia, Salvador, Bahia.

\section{Correspondência}

Lia da Rocha Lordelo

Rua Rogério de Faria, 106/302, Rio Vermelho. CEP: 41940 300. Salvador-BA

\section{Agradecimento}

A CAPES pela bolsa de mestrado. 